\title{
Efficient synthesis of dihydropyrimidinones via a three-component Biginelli-type reaction of urea, alkylaldehyde and arylaldehyde
}

\author{
Haijun Qu, Xuejian Li, Fan Mo and Xufeng Lin*
}

Open Access

\begin{abstract}
A one-pot three-component synthesis of dihydropyrimidinones via a molecular iodine-catalyzed tandem reaction of simple readily available mono-substituted urea, alkylaldehyde, and arylaldehyde has been developed. The reaction proceeds with high chemo- and regioselectivity to give highly diverse dihydropyrimidinones in reasonable yields under mild reaction conditions. Moreover, the first catalytic enantioselective version of this reaction was also realized by using chiral spirocyclic SPINOL-phosphoric acids.
\end{abstract}

\section{Introduction}

The dihydropyrimidinones (DHPMs) have exhibited interesting and multifaceted biological activities, such as antiviral, antitumor, antibacterial, and antiflammatory properties as well as calcium channel modulating activity [1,2]. As a consequence, the synthesis of dihydropyrimidinone derivatives bearing diverse substitution patterns has attracted significant attention since its discovery 120 years ago in 1893 by the Italian chemist Pietro Biginelli $[3,4]$. Among them, the Biginelli multicomponent reaction, involving a multicomponent condensation of aldehyde, $\beta$-ketoester, and urea, provides an easy access to the preparation of DHPMs, because multicomponent reactions (MCRs) are considered with high facileness, efficiency and economy in organic chemistry [5-8]. Recently, many one-pot variants of Biginelli-type reactions for the preparation of novel DHPMs using various active methylene compounds [9-15], such as enaminone, cyclic $\beta$-diketones, acetophenone, benzocyclic ketones and $\beta$-oxodithioesters etc., have also been developed to be carried out in the presence of a Lewis or protic acid. It is still highly valuable to develop new direct approaches for the efficient synthesis of DHPMs due to the continued importance of the dihydropyrimidinone core in organic and medicinal chemistry.

Recently, molecular iodine has emerged as an inexpensive, lowtoxic catalyst with moderate Lewis acidity and water-tolerance in organic chemistry [16]. Previously, we have developed some 
molecular iodine-catalyzed organic transformations [17-21], herein we describe the first molecular iodine-catalyzed one-pot three-component Biginelli-type synthesis of DHPMs from simple readily available mono-substituted urea, alkylaldehyde, and arylaldehyde under mild reaction conditions [22-24]. The present method is suitable for a wide range of substrates, and especially for functionalized arylaldehydes. The first catalytic enantioselective version of this reaction is also presented by using chiral spirocyclic SPINOL-phosphoric acids (SPAs) as the catalyst.

\section{Results and Discussion}

Initially, the mixture of $N$-methylurea (1a, $2.5 \mathrm{mmol}$ ), phenylacetaldehyde (2a, $2.5 \mathrm{mmol})$ and $p$-nitrobenzaldehyde (3a, $3.75 \mathrm{mmol}$ ) in toluene $(3 \mathrm{~mL})$ was treated with $10 \mathrm{~mol} \%$ of iodine under reflux for 12 hours. The functionalized dihydropyrimidinone $4 \mathrm{a}$ was obtained in $56 \%$ yield and the structure of the product was clearly assigned by both abundant spectral analysis and X-ray single crystal diffraction (Figure 1).

For optimization of the reaction conditions, various trial reactions were conducted with a combination of $N$-methylurea (1a), phenylacetaldehyde (2a) and $p$-nitrobenzaldehyde (3a) in order to obtain the best yield of $\mathbf{4 a}$, which is summarized in Table 1 . We examined some organic solvents, and have noted that acetonitrile was the most suitable solvent among others, such as toluene, 1,4-dioxane, THF, DCE, and DCM (Table 1, entries $1-6)$. The catalyst loading (10\%) gave the good result for the formation of the desired product (Table 1, entries 6-8).

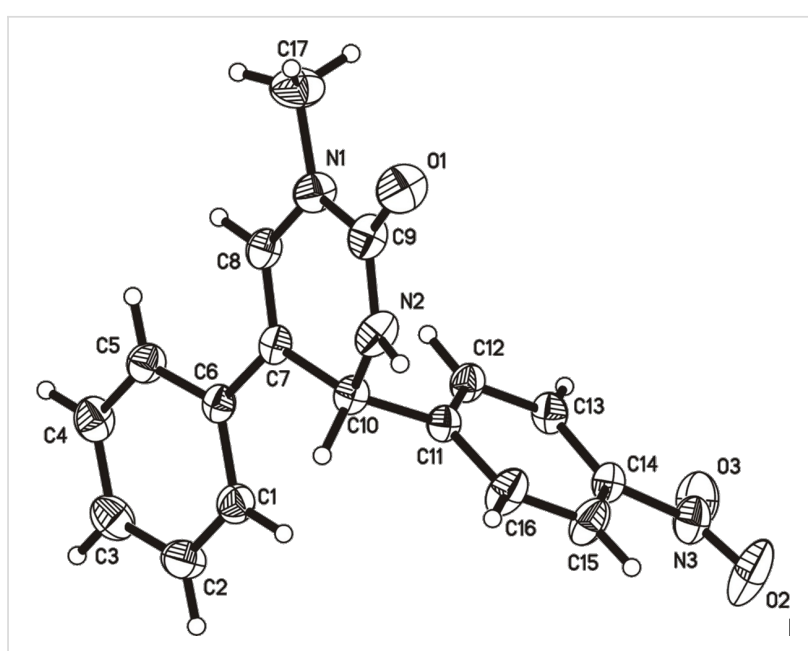

Figure 1: X-ray crystal structure of $4 a$.

The substrate scope of the molecular iodine-catalyzed one-pot three-component Biginelli-type reaction was then investigated, and the results were presented in Table 2. First, we examined the scope of the aromatic aldehydes 3 . Various aromatic aldehydes $\mathbf{3 a}-\mathbf{3 l}$ and furfural (3m) were suitable substrates, and the expected products were obtained in moderate isolated yields (39-70\%) (Table 2, entries 1-13). Electron-withdrawing as well as electron-donating groups on aromatic rings were tolerated, although the latter gave slightly reduced yields. It is noted that a halogen group on the aromatic ring was well tolerated to give the desired products, which can participate in subsequent transformations such as cross-coupling reactions (Table 2, entries

Table 1: Optimization of reaction conditions. ${ }^{2}$

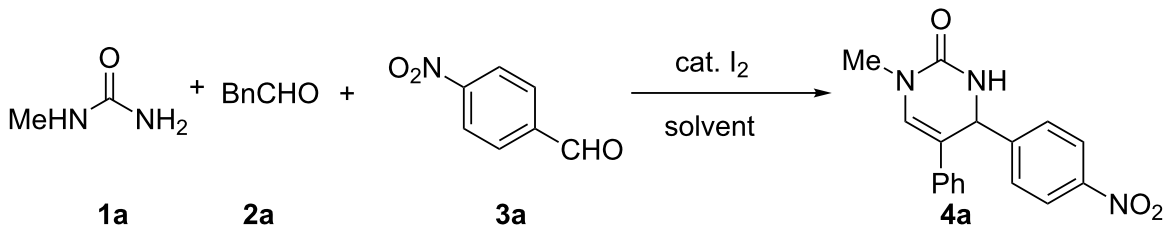

\begin{tabular}{llllll}
\hline Entry & lodine $(\mathrm{mol} \%)$ & Solvent & $T$ & $t(\mathrm{~h})$ & ${\text { Yield }(\%)^{\mathrm{b}}}^{\mathrm{m}}$ \\
\hline 1 & 10 & toluene & reflux & 12 & 56 \\
2 & 10 & 1,4 -dioxane & reflux & 12 & 53 \\
3 & 10 & THF & reflux & 12 & 58 \\
4 & 10 & DCE & reflux & 12 & 52 \\
5 & 10 & DCM & rt & 24 & 70 \\
6 & 10 & MeCN & reflux & 12 & 70 \\
7 & 15 & MeCN & reflux & 10 & 58 \\
8 & 5 & MeCN & reflux & 24 & 0 \\
9 & 0 & MeCN & reflux & 12 & 70 \\
\hline
\end{tabular}

aAll the reactions were carried out using $1 \mathbf{a}(2.5 \mathrm{mmol}), \mathbf{2 a}(2.5 \mathrm{mmol})$, and $\mathbf{3 a}(3.75 \mathrm{mmol})$ in $3 \mathrm{~mL}$ solvent. ${ }^{\mathrm{b}} /$ solated yields. 
Table 2: One-pot synthesis of dihydropyrimidinones. ${ }^{a}$

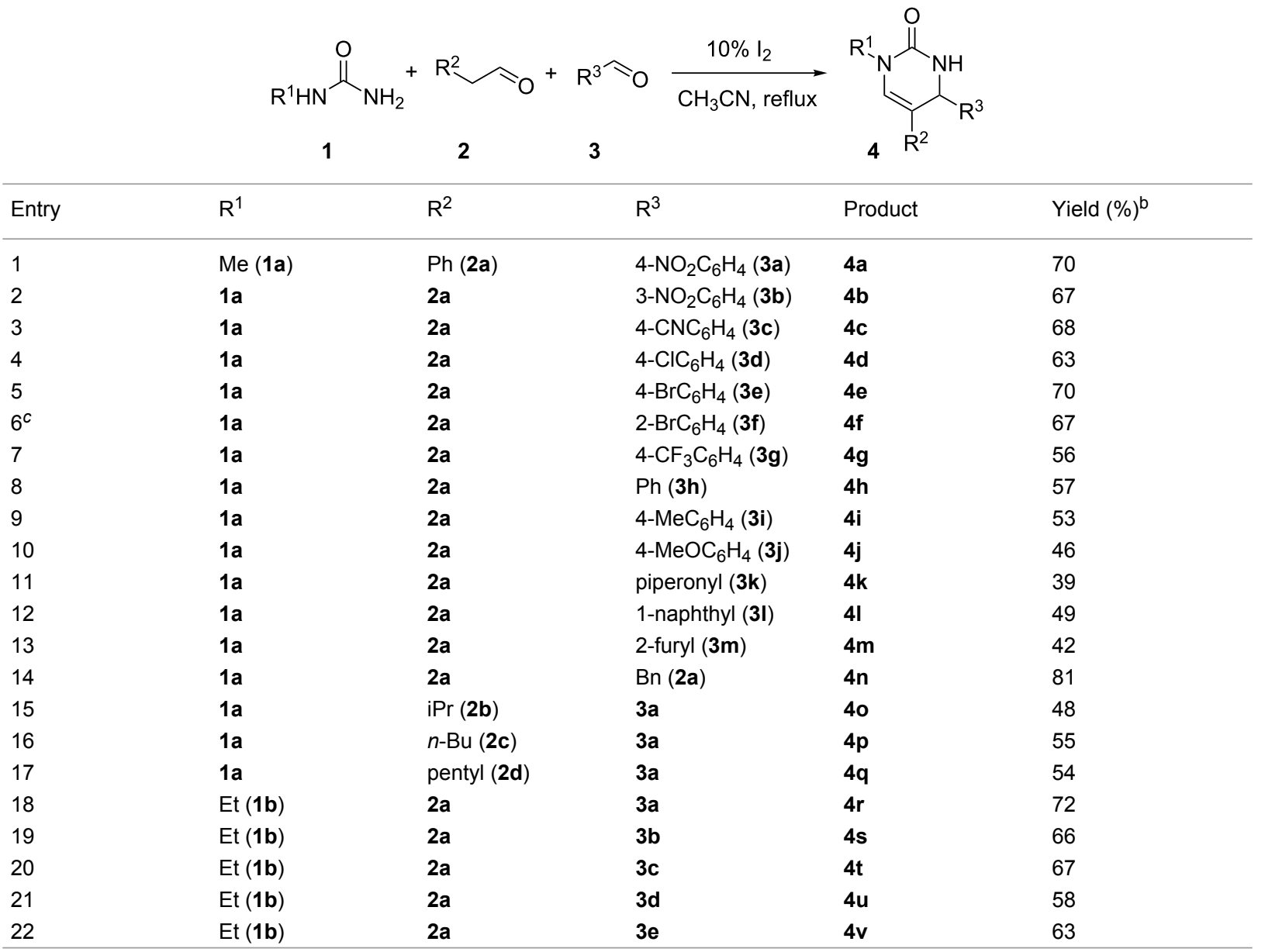

aAll the reactions were carried out using $1(2.5 \mathrm{mmol}), 2(2.5 \mathrm{mmol}), 3(3.75 \mathrm{mmol})$, and iodine $(0.25 \mathrm{mmol})$ in $3 \mathrm{~mL} \mathrm{MeCN} \mathrm{at} \mathrm{reflux} \mathrm{for} 12 \mathrm{~h}$. b/solated yields.

4-6). Furthermore, when phenylacetaldehyde (2a) was used instead of an aromatic aldehyde, product $4 \mathbf{n}$ was isolated with good yield (81\%; Table 2, entry 14). Subsequently, we investigated the scope of substituted acetaldehydes $\mathbf{2}$ (Table 2, entries 15-17). The variation of the alkyl substituent of acetaldehydes 2 is well tolerated to provide the desired products $\mathbf{4 0 - 4 q}$ in $48-55 \%$ isolated yields. Finally, $N$-ethylurea $\mathbf{1 b}$ was also investigated in the one-pot three-component reaction, and the reactions proceeded smoothly to give the corresponding dihydropyrimidinones $\mathbf{4 r}-\mathbf{4 v}$ in $58-72 \%$ isolated yields (Table 2 , entries 18-22). Based on the experimental results above, the iodine-catalyzed Biginelli-type reaction proved to be of broad scope and provides higher yields of dihydropyrimidinones than the earlier described method with $\mathrm{BF}_{3} \cdot \mathrm{Et}_{2} \mathrm{O}$ as the catalyst.

Molecular iodine is a mild catalyst with moderate Lewis acidity. Thus, a possible mechanism was proposed in Scheme 1. The first step is the condensation via the primary nitrogen of mono- substituted urea $\mathbf{1}$ with the aromatic aldehyde $\mathbf{3}$ to give the intermediate 5. Then, the enamide $\mathbf{6}$ is generated through the condensation of imine $\mathbf{5}$ with substituted acetaldehyde $\mathbf{2}$. This

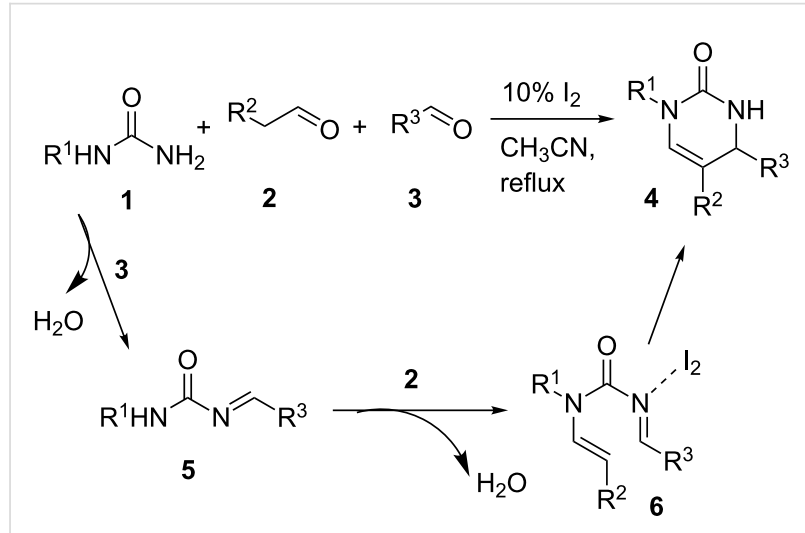

Scheme 1: Possible mechanism. 
could then undergo an iodine-catalytic intramolecular cyclisation to afford the final dihydropyrimidinone 4.

Based on the observations above, a preliminary investigation on the catalytic asymmetric version was performed. Recently, our group has developed a novel class of spirocyclic SPINOL-phosphoric acids derived from chiral 1,1'-spirobiindane-7,7'-diol, which could effectively catalyze some highly enantioselective reactions [25-31]. These previous successes led us to envision that SPINOL-phosphoric acids would effectively catalyze the enantioselective three-component reaction of mono-substituted ureas 1, alkylaldehydes $\mathbf{2}$ and arylaldehydes $\mathbf{3}$ to generate enantioenriched dihydropyrimidinones 4 [32-35].

In our initial study, we examined the multicomponent model reaction between $N$-methylurea 1a, phenylacetaldehyde $\mathbf{2 a}$, and $p$-nitrobenzaldehyde 3a. As shown in Table 3, optimization of the reaction conditions revealed that toluene was the best solvent, chiral SPINOL-phosphoric acid 5a was the best catalyst and the best temperature was room temperature, which afforded product $\mathbf{4 a}$ with $77 \%$ ee in $62 \%$ yield (Table 3, entry 4). With these reaction conditions identified, the variation of the reaction substrates was well tolerated to provide the desired products with up to $77 \%$ ee (Figure 2). Although the enantioselectivity was low to moderate, it should be noted that this is the first catalytic enantioselective version of this multicomponent reaction.

\section{Conclusion}

In conclusion, we have demonstrated the first efficient, molecular iodine-catalyzed three-component synthesis of dihydropyrimidinones starting from simple readily available monosubstituted ureas, alkylaldehydes, and arylaldehydes. A significant progress was obtained with an extremely broad substrate scope, giving the corresponding DHPMs with reasonable yields under mild reaction conditions. Moreover, the catalytic asym-

Table 3: Optimization of the asymmetric reaction conditions. ${ }^{\text {a }}$

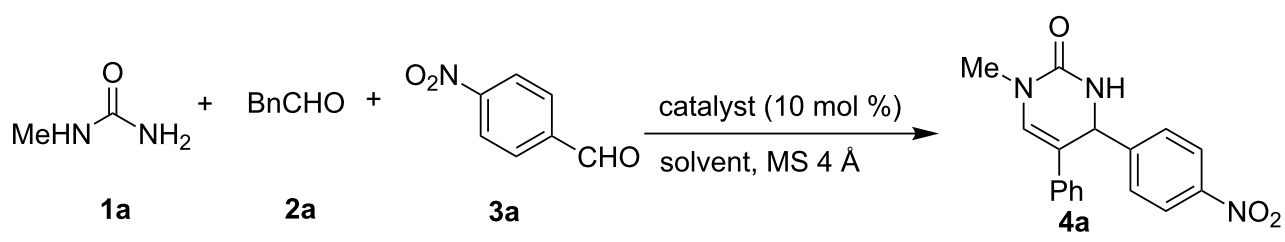

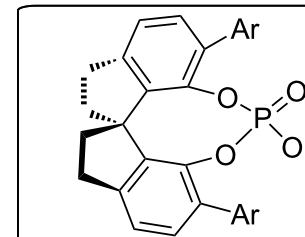

(S)-5

5a: $\mathrm{Ar}=1$-naphthyl

5b: $\mathrm{Ar}=4-\mathrm{ClC}_{6} \mathrm{H}_{4}$

5c: $\mathrm{Ar}=3,5-\left(\mathrm{CF}_{3}\right)_{2} \mathrm{C}_{6} \mathrm{H}_{3}$

5d: $\mathrm{Ar}=9$-phenanthryl

5e: $\mathrm{Ar}=9$-anthryl

5f: $\mathrm{Ar}=\mathrm{H}$

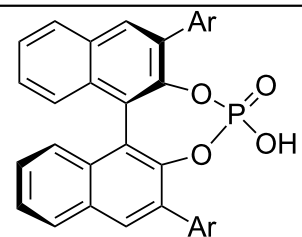

$(R)-6$

$\mathrm{Ar}=3,5-\left(\mathrm{CF}_{3}\right)_{2} \mathrm{C}_{6} \mathrm{H}_{3}$

\begin{tabular}{llllll}
\hline Entry & Catalyst & Solvent & $T\left({ }^{\circ} \mathrm{C}\right)$ & Yield $(\%)^{\mathrm{b}}$ & ee $^{\mathrm{c}}$ \\
\hline 1 & $\mathbf{5 a}$ & $\mathrm{CH}_{3} \mathrm{CN}$ & $\mathrm{rt}$ & 75 & 17 \\
2 & $\mathbf{5 a}$ & $\mathrm{CH}_{3} \mathrm{CN}$ & 0 & 51 & 34 \\
3 & $\mathbf{5 a}$ & xylene & $\mathrm{rt}$ & 60 & 72 \\
4 & $\mathbf{5 a}$ & toluene & $\mathrm{rt}$ & 62 & - \\
5 & $\mathbf{5 a}$ & toluene & 0 & 0 & 67 \\
6 & $\mathbf{5 a}$ & toluene & 50 & 65 & 34 \\
7 & $\mathbf{5 b}$ & toluene & 50 & 39 & 42 \\
8 & $\mathbf{5 c}$ & toluene & 50 & 30 & 58 \\
9 & $\mathbf{5 d}$ & toluene & 50 & 41 & 60 \\
10 & $\mathbf{5 e}$ & toluene & 50 & 28 & 12 \\
11 & $\mathbf{5 f}$ & toluene & 50 & 58 & - \\
12 & $\mathbf{6}$ & toluene & 50 & 0 & \\
\hline
\end{tabular}

aReaction conditions: Catalyst (10 mol \%, $0.02 \mathrm{mmol}), 1 \mathrm{a}(0.2 \mathrm{mmol}), 2 \mathrm{a}(0.2 \mathrm{mmol}), 3 \mathrm{a}(0.3 \mathrm{mmol}), \mathrm{MS} 4 \AA(0.1 \mathrm{~g})$, solvent $(1 \mathrm{~mL}), 2 \mathrm{days}$. blsolated yields. 'Determined by chiral HPLC analysis. 


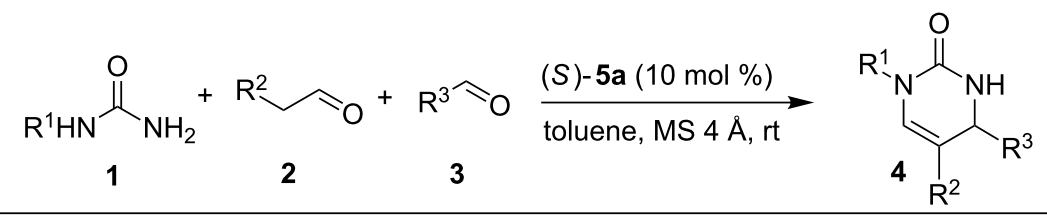<smiles>CN1C=C(c2ccccc2)C(c2ccc([N+](=O)[O-])cc2)NC1=O</smiles>

4a

$62 \%, 77 \%$ ee<smiles>CN1C=C(c2ccccc2)C(c2ccc(Br)cc2)NC1=O</smiles>

4e

$43 \%, 53 \%$ ee<smiles>CN1C=C(c2ccccc2)C(c2cccc([N+](=O)[O-])c2)NC1=O</smiles>

4b

$57 \%, 75 \%$ ee<smiles>CN1C=C(c2ccccc2)C(c2ccccc2Br)NC1=O</smiles>

$4 \mathbf{f}$

$45 \%, 20 \%$ ee<smiles>CN1C=C(c2ccccc2)C(c2ccc(C#N)cc2)NC1=O</smiles>

4c

$55 \%, 64 \%$ ee<smiles>COc1ccc(C2NC(=O)N(C)C=C2c2ccccc2)cc1</smiles>

4j

$38 \%, 33 \%$ ee<smiles>CN1C=C(c2ccccc2)C(c2ccc(Cl)cc2)NC1=O</smiles>

$47 \%, 32 \%$ ee

Figure 2: Scope of the enantioselective reaction. Reaction conditions: $5 \mathrm{a}(10 \mathrm{~mol} \%, 0.02 \mathrm{mmol}), \mathbf{1}(0.2 \mathrm{mmol}), 2(0.2 \mathrm{mmol}), 3(0.3 \mathrm{mmol}), \mathrm{MS} 4 \AA$ $(0.1 \mathrm{~g})$, toluene $(1 \mathrm{~mL}), \mathrm{rt}, 2$ days. Isolated Yields were given. The ee's were determined by chiral HPLC.

metric version of this multicomponent reaction has also been developed to a straightforward synthesis of enantiomerically enriched DHPMs by using a chiral SPINOL-phosphoric acid as the catalyst.

\section{Crystallographic Data}

Single crystal data for compound 4a (CCDC 918944) has been deposited in the Cambridge Crystallographic Data Centre. These data can be obtained free of charge via http:// www.ccdc.cam.ac.uk/data request/cif.

\section{Supporting Information}

\section{Supporting Information File 1}

Experimental details and spectroscopic data.

[http://www.beilstein-journals.org/bjoc/content/ supplementary/1860-5397-9-320-S1.pdf]

\section{Acknowledgements}

This work was supported by the National Natural Foundation of China (21272202 and J1210042) and the Fundamental Research Funds for the Central Universities.

\section{References}

1. Kappe, C. O. Eur. J. Med. Chem. 2000, 35, 1043-1052. doi:10.1016/S0223-5234(00)01189-2

2. Chitra, S.; Devanathan, D.; Pandiarajan, K. Eur. J. Med. Chem. 2010, 45, 367-371. doi:10.1016/j.ejmech.2009.09.018 And references cited therein.

3. Biginelli, P. Gazz. Chim. Ital. 1893, 23, 360-413.

4. Kappe, O. C. Acc. Chem. Res. 2000, 33, 879-888. doi:10.1021/ar000048h

5. Zhu, J.; Bienayme, H. Multicomponent Reactions; Wiley-VCH: Weinheim, Germany , 2005. doi:10.1002/3527605118

6. Dömling, A. Chem. Rev. 2006, 106, 17-89. doi:10.1021/cr0505728

7. Tejedor, D.; Garcia-Tellado, F. Chem. Soc. Rev. 2007, 36, 484-491. doi:10.1039/b608164a

8. Müller, T. J. J. Beilstein J. Org. Chem. 2011, 7, 960-961. doi:10.3762/bjoc.7.107

9. Wan, J.-P.; Pan, Y.-J. Chem. Commun. 2009, 2768-2770. doi:10.1039/b901112a

10. Zheng, L.-Y.; Cai, C. J. Comb. Chem. 2010, 12, 35-40. doi:10.1021/cc9000983

11. Wang, Z.-T.; Xu, L.-W.; Xia, C.-G.; Wang, H.-Q. Tetrahedron Lett. 2004, 45, 7951-7953. doi:10.1016/j.tetlet.2004.08.107

12. Stadler, A.; Kappe, C. O. J. Comb. Chem. 2001, 3, 624-630. doi:10.1021/cc010044j

13. Abelman, M. M.; Smith, S. C.; James, D. R. Tetrahedron Lett. 2003, 44, 4559-4562. doi:10.1016/S0040-4039(03)00985-7 
14. Zhu, Y.-L.; Huang, S.-L.; Pan, Y.-J. Eur. J. Org. Chem. 2005, 2354-2367. doi:10.1002/ejoc.200400845

15. Singh, O. M.; Devi, N. S. J. Org. Chem. 2009, 74, 3141-3144. doi:10.1021/jo802585b

16. Tekale, S. U.; Kauthale, S. S.; Dake, S. A.; Sarda, S. R.; Pawar, R. P. Curr. Org. Chem. 2012, 16, 1485-1501.

doi:10.2174/138527212800672574

And references cited therein.

17. Lin, X.-F.; Cui, S.-L.; Wang, Y.-G. Tetrahedron Lett. 2006, 47, 4509-4512. doi:10.1016/j.tetlet.2006.03.123

18. Lin, X.-F.; Cui, S.-L.; Wang, Y.-G. Tetrahedron Lett. 2006, 47, 3127-3130. doi:10.1016/j.tetlet.2006.02.136

19. Wang, J.; Xu, F.-X.; Lin, X.-F.; Wang, Y.-G. Tetrahedron Lett. 2008, 49, 5208-5210. doi:10.1016/j.tetlet.2008.06.024

20. Lin, X.; Dai, X.; Mao, Z.; Wang, Y. Tetrahedron 2009, 65, 9233-9237. doi:10.1016/j.tet.2009.09.007

21. Li, X.; Mao, Z.; Wang, Y.; Chen, W.; Lin, X. Tetrahedron 2011, 67, 3858-3862. doi:10.1016/j.tet.2011.03.087

22. Folkers, K.; Johnson, T. B. J. Am. Chem. Soc. 1933, 55, 3361-3368. doi:10.1021/ja01335a053

23. Timokhin, V. I.; Stahl, S. S. J. Am. Chem. Soc. 2005, 127, 17888-178993. doi:10.1021/ja0562806

24. Bailey, C. D.; Houlden, C. E.; Bar, G. L. J.; Lloyd-Jones, G. C.; Booker-Milburn, K. I. Chem. Commun. 2007, 2932-2934. doi:10.1039/b707361e

25. Xu, F.; Huang, D.; Han, C.; Shen, W.; Lin, X.; Wang, Y. J. Org. Chem. 2010, 75, 8677-8680. doi:10.1021/jo101640z

26. Huang, D.; Xu, F.; Lin, X.; Wang, Y. Chem.-Eur. J. 2012, 18, 3148-3152. doi:10.1002/chem.201103207

27. Xu, F.; Huang, D.; Lin, X.; Wang, Y. Org. Biomol. Chem. 2012, 10, 4467-4470. doi:10.1039/c2ob25663k

28. Huang, D.; Xu, F.; Chen, T.; Wang, Y.; Lin, X. RSC Adv. 2013, 3, 573-578. doi:10.1039/c2ra22796g

29. Li, X.; Zhao, Y.; Qu, H.; Mao, Z.; Lin, X. Chem. Commun. 2013, 49, 1401-1403. doi:10.1039/c2cc38349g

30. Zhao, Y.; Li, X.; Mo, F.; Li, L.; Lin, X. RSC Adv. 2013, 3, 11895-11901. doi:10.1039/c3ra40958a

31. Čorić, I.; Müller, S.; List, B. J. Am. Chem. Soc. 2010, 132, 17370-17373. doi:10.1021/ja108642s

See for a simultaneous report on the development of chiral SPINOL-phosphoric acid.

32. Huang, Y.; Yang, F.; Zhu, C. J. Am. Chem. Soc. 2005, 127, 16386-16387. doi:10.1021/ja056092f

33. Chen, X.-H.; Xu, X.-Y.; Liu, H.; Cun, L.-F.; Gong, L.-Z. J. Am. Chem. Soc. 2006, 128, 14802-14803. doi:10.1021/ja065267y

34. Goss, J. M.; Schaus, S. E. J. Org. Chem. 2008, 73, 7651-7656. doi:10.1021/jo801463j

35. Heravi, M. M.; Asadi, S.; Lashkariani, B. M. Mol. Diversity 2013, 17, 389-407. doi:10.1007/s11030-013-9439-9

\section{License and Terms}

This is an Open Access article under the terms of the Creative Commons Attribution License

(http://creativecommons.org/licenses/by/2.0), which permits unrestricted use, distribution, and reproduction in any medium, provided the original work is properly cited.

The license is subject to the Beilstein Journal of Organic Chemistry terms and conditions:

(http://www.beilstein-journals.org/bjoc)

The definitive version of this article is the electronic one which can be found at:

doi:10.3762/bjoc. 9.320 